\title{
Amelioration of Salt Stress on Bermudagrass by the Fungus Aspergillus aculeatus
}

\author{
Yan Xie, ${ }^{1}$ Shijuan Han, ${ }^{1,2}$ Xiaoning Li, ${ }^{1,2}$ Erick Amombo,, ${ }^{1,2}$ and Jinmin $\mathbf{F u}^{1}$ \\ ${ }^{1}$ Key Laboratory of Plant Germplasm Enhancement and Specialty Agriculture, Wuhan Botanical Garden, Chinese Academy \\ of Sciences, Wuhan City, Hubei, 430074, P.R. China; and ${ }^{2}$ Graduate University of Chinese Academy of Sciences, Beijing \\ 100049, P.R. China
}

Accepted 19 November 2016.

\begin{abstract}
There is considerable evidence that plant abiotic-stress tolerance can be evoked by the exploitation of a globally abundant microbe. A. aculeatus, which was initially isolated from the rhizosphere of bermudagrass, has been shown to increase heavy metal tolerance in turfgrasses. Here, we report on the potential of A. aculeatus to induce tolerance to salt stress in bermudagrass. Physiological markers for salt stress, such as plant growth rate, lipid peroxidation, photosynthesis, and ionic homeostasis were assessed. Results indicated that strain $A$. aculeatus produced indole-3-acetic acid (IAA) and siderophores and exhibited a greater capacity for $\mathrm{Na}^{+}$absorption under salt stress. The plant inoculation by $A$. aculeatus increased plant growth and attenuated the $\mathrm{NaCl}$-induced lipid peroxidation in roots and leaves of bermudagrass. The fungus significantly elevated the amount of IAA and glutathione and slightly enhanced photosynthetic efficiency of salt-treated bermudagrass. Tissues of inoculated plants had significantly increased concentrations of $\mathrm{K}^{+}$but lower $\mathrm{Na}^{+}$ concentrations than those of uninoculated regimes. It appears that the role of $A$. aculeatus in alleviating bermudagrass salt stress is partly to produce IAA, to increase the activity of antioxidases, to absorb $\mathrm{Na}^{+}$by fungal hyphae, and to prevent the plant from ionic homeostasis disruption.
\end{abstract}

Soil salinization is a serious factor restricting the expansion of agriculture, animal husbandry, and forestry around the globe. Salinity problems are prominent in arid and semiarid regions, including fertile alluvial plains, valleys, densely populated areas, and the coastal regions (Pessarakli and Szabolcs 2011). Salinity is becoming particularly widespread in many regions. Globally, more than $20 \%$ of agricultural land and approximately $50 \%$ of irrigated land is affected by salinity, which poses a serious threat to more than $50 \%$ of all arable lands by the year 2050 (Flowers and Yeo 1995; Wang et al. 2003).

Highly saline soil from irrigation water leads to a series of morphological, physiological, biochemical, and molecular changes that adversely affect plant growth and productivity (Wang et al. 2000). Under saline conditions, plants are exposed to three types of stresses, including ion toxicity, desiccation, and disruptions in the mineral nutrition of the plant (Blumwald 2000). Excessive ions $\left(\mathrm{Na}^{+}\right.$and $\left.\mathrm{Cl}^{-}\right)$in the rhizosphere causes injury

Corresponding author: J. Fu; E-mail: jfu@wbgcas.cn; Telephone: +86027 87511506 .

*The $\boldsymbol{e}$-Xtra logo stands for "electronic extra" and indicates that two supplementary figures and one supplementary table are published online.

@ 2017 The American Phytopathological Society to plant roots, followed by their gradual accumulation in the aerial parts, with heavy damage to plant metabolism, which leads to stunted growth and subsequently reduced yield (Shannon 1997). Furthermore, the excessive uptake of $\mathrm{Na}^{+}$and $\mathrm{Cl}^{-}$can limit the uptake of other mineral nutrition (e.g., $\mathrm{K}^{+}, \mathrm{Ca}^{2+}, \mathrm{Mg}^{2+}$ ), and the lack of nutritional elements causes adverse effects on ionic homeostasis, which restrains cell elongation and division, causing premature leaf aging and reducing leaf and root growth (Munns 2002; Zhu 2001). Dionisio-Sese and Tobita (2000) reported that the net photosynthetic rate declined with increasing levels of salinity stress of four rice varieties (Dionisio-Sese and Tobita 2000). This might be due to the direct effect of salt on stomatal resistance via a reduction in guard cell turgor (Maxwell and Johnson 2000). Therefore, salinity is considered as one of the most decisive environmental factors limiting plant growth and productivity.

To counter negative effects of soil salinity, selection of salt tolerant plants, desalination of soil by leaching excessive salts, and application of biological processes such as plant-microbe interactions, alone or in combination, can be employed (Bandou et al. 2006; Feng et al. 2002; Munns 2005). Among the remediation tools, the desalination of soils relies on a high chemical input, hence, it is not economically viable for sustainable agriculture and is achieved at the expense of the environment (Bandou et al. 2006; Waller et al. 2005). There is considerable evidence that abiotic-stress tolerance can be evoked in plants by the exploitation of globally abundant microbes, which live in reciprocally beneficial relationships with plants (Waller et al. 2005). For example, a fungal endophyte of tall fescue (Epichlö coenophiala) significantly increases plantavailable water and aggregate stability of rhizosphere soil and, thereby, might raise water productivity in drought periods (Hosseini et al. 2015a and b, 2016). Piriformospora indica, a plant root-colonizing basidiomycete fungus, was shown to provide strong growth-promoting activity during its symbiosis with barley (Baltruschat et al. 2008; Waller et al. 2005). Previous studies have demonstrated that the Epichloë spp. usually infect cool-season grasses such as tall fescue, meadow fescue, and perennial ryegrass and alter soil biological and biochemical properties through the production of alkaloids, phenolic compounds, and other secondary metabolites, such as carbohydrates and proline (Hosseini et al. 2015a, 2016; Malinowski et al. 2000). Microorganisms have been reported to enhance the growth of plants by stimulating plant growth, increasing mineral nutrition, and minimizing excessive ion uptake $\left(\mathrm{Na}^{+}\right.$and $\left.\mathrm{Cl}^{-}\right)$ under salt stress (Li et al. 2012; Smith and Read 2010; Waller et al. 2005). Furthermore, mutualistic symbiosis with mycorrhizal and endophytic fungi can confer salt tolerance to plants grown in saline soils (Baltruschat et al. 2008). Arbuscular 
mycorrhizal fungi enhance the growth of host plants by improving nutritional mineral uptake in soils (Al-Karaki 2000; Bandou et al. 2006; Tian et al. 2004). Mycorrhiza can help moderately salt-tolerant plants to prevent excessive translocation of ions to the shoot and leaf tissues, eventually improving salt tolerance (Giri and Mukerji 2004). However, mycorrhizal plants often show enhanced susceptibility to biotrophic leaf pathogens (Shaul et al. 1999).

Aspergillus aculeatus is a fungus, belonging to the genus Aspergillus, that was isolated from the rhizosphere of bermudagrass in Hunan province, Central China (Xie et al. 2014). Our previous study showed that root colonization and association of fungal hyphae with roots resulted in promotion of plant growth, higher yields, and reduction of $\mathrm{Cd}$ translocation to plant shoots under unfavorable conditions (Xie et al. 2014). In addition, A. aculeatus can be easily cultivated on synthetic media, allowing for large-scale propagation in contrast to arbuscular mycorrhizal fungi. Therefore, A. aculeatus might be possibly used in plant production in saline environments. The mechanism of $A$. aculeatus-induced salt tolerance has not yet been investigated. Bermudagrass (Cynodon dactylon) is a perennial grass distributed across all continents and on most oceanic islands between latitudes of approximately 45 degrees north and south (Xie et al. 2016). Bermudagrass is a widely used turf and forage that is well-adapted to salt sprays and coastal regions (Hu et al. 2015). In addition, this grass is naturally associated with A. aculeatus fungi, but the role of $A$. aculeatus fungi in bermudagrass growth, photosynthesis, and nutrition under salt stress remains unknown. The aim of the present study was to investigate the A. aculeatus-mediated protective plant responses to moderate $(200 \mathrm{mM} \mathrm{NaCl})$ and high $(400 \mathrm{mM} \mathrm{NaCl})$ salt stress in
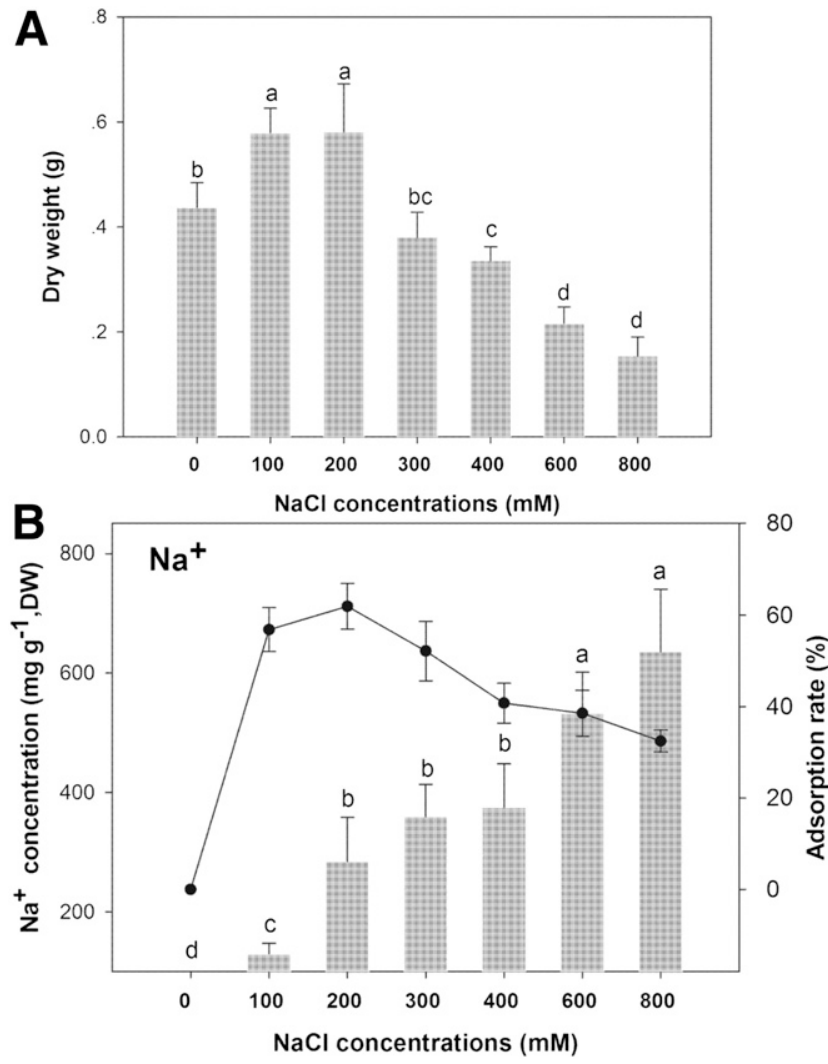

Fig. 1. The influence of the salt treatment on the $\mathbf{A}$, dry biomass and $\mathbf{B}$, total $\mathrm{Na}^{+}$uptake (in milligrams per gram of dry weight [DW]) of Aspergillus aculeatus. Error bars are \pm standard deviation $(n=4)$. Columns marked with the same lower case letter were not significantly different among treatments $(P<0.05)$. bermudagrass. In order to elucidate physiological responses of A. aculeatus-colonized bermudagrass to salinization, we measured important indicators of salt stress, such as plant growth and productivity, lipid peroxidation, photosynthetic rates, and mineral nutrition.

\section{RESULTS}

Salt resistance and uptake of the strains.

The A. aculeatus strain was found to exhibit strong salt resistance characteristics, as shown by the markedly increased biomass by moderate salt stress when compared with unsalinized control (Fig. 1A). The inhibition effect of $\mathrm{NaCl}$ on growth was observed when A. aculeatus strains were subjected to $400 \mathrm{mM} \mathrm{NaCl}$. The $\mathrm{Na}^{+}$uptake and the percentage of adsorption by the A. aculeatus strains were determined over a concentration range of 100 to $800 \mathrm{mM} \mathrm{NaCl}$ for $24 \mathrm{~h}$ of adsorption is represented in Figure 1B. The accumulation of $\mathrm{Na}^{+}$in A. aculeatus strains significantly increased with increasing salinity level. The removal efficiency was found to be higher at lower initial concentrations of $\mathrm{NaCl}$. The adsorptive rate of $\mathrm{Na}^{+}$ reached maximum (62\%) at $200 \mathrm{mM} \mathrm{NaCl}$ concentrations and, then, decreased as $\mathrm{NaCl}$ concentrations increased.

\section{Characteristics of the strains.}

The A. aculeatus strains had the capacity to produce indole3 -acetic acid (IAA) and siderophore in culture when the medium was supplemented with L-tryptophan (Table 1). When salinity increased from 200 to $800 \mathrm{mM}$, the concentration of IAA decreased, whereas the concentration of siderophore significantly increased when compared with the control.

\section{A. aculeatus accelerates the growth of bermudagrass under salt stress.}

Bermudagrass treated with high concentrations of salt (400 mM $\mathrm{NaCl}$ ) for 2 weeks showed stunted growth and underwent early senescence. The shoot growth rate slightly decreased under moderate $(200 \mathrm{mM} \mathrm{NaCl})$ saline conditions (Fig. 2A). Moderate salinity caused a slight but not significant increase in root growth rate of bermudagrass plants (Fig. 2B). When inoculated bermudagrass plants were exposed to high salt concentrations, they showed reduced shoot and root growth rate compared with the control. However, the detrimental effect of high salt stress was partially ameliorated by A. aculeatus, as shown by the fact that inoculated plants showed higher shoot and root growth rate than their control plant counterparts (Fig. 2A and B). More interestingly, inoculated bermudagrass plants showed obviously greater root growth rate compared with uninoculated plants regardless of $\mathrm{NaCl}$ level (Fig. 2B). Moderate saline stress increased the root/shoot growth rate ratio for uninoculated plants (Fig. 2C). A. aculeatus inoculation caused a significant increase in the root/shoot growth rate ratio, when compared with uninoculated plants, regardless of $\mathrm{NaCl}$ level.

Turf quality of both treated plants declined with the increase in $\mathrm{NaCl}$ concentration and, to a larger extent, in uninoculated bermudagrass than inoculated plants. Inoculations with

Table 1. Characteristics of the Aspergillus aculeatus strains ${ }^{2}$

\begin{tabular}{lccccc}
\hline & \multicolumn{5}{c}{ NaCl concentration $(\mathbf{m M})$} \\
\cline { 2 - 6 } & $\mathbf{0}$ & $\mathbf{1 0 0}$ & $\mathbf{2 0 0}$ & $\mathbf{4 0 0}$ & $\mathbf{8 0 0}$ \\
\hline $\begin{array}{l}\text { Indole-3-acetic acid } \\
\text { (pmol per liter) }\end{array}$ & $11.3 \mathrm{a}$ & $9.7 \mathrm{~b}$ & $10.3 \mathrm{ab}$ & $8.1 \mathrm{c}$ & $8.2 \mathrm{c}$ \\
Siderophore production (\%) & $25.0 \mathrm{~b}$ & $16.8 \mathrm{c}$ & $22.2 \mathrm{~b}$ & $25.0 \mathrm{~b}$ & $34.0 \mathrm{a}$ \\
\hline $\begin{array}{l}\text { z Values are means of five samples. Columns marked with the same lower } \\
\text { case letter were not significantly different among treatments }(P<0.05) .\end{array}$
\end{tabular}


A. aculeatus subsequently improved the turf quality compared with $\mathrm{NaCl}$-only regimes when bermudagrass was subjected to high level salt treatment $(400 \mathrm{mM} \mathrm{NaCl})$. Chl decreased with the increasing $\mathrm{NaCl}$ concentration for uninoculated bermudagrass plants (Supplementary Fig. 1). No significant reduction in Chl was observed for inoculated plants with the increase in $\mathrm{NaCl}$ concentration. Among plants grown in a highly saline environment, $\mathrm{Chl}$ of inoculated bermudagrass plants was significantly higher when compared with the uninoculated regime.

\section{A. aculeatus reduces lipid peroxidation and $\mathrm{H}_{2} \mathrm{O}_{2}$ level in salt-treated bermudagrass.}

The degree of oxidative damage in the root and leaf was examined by determining the level of lipid peroxidation, which was estimated from the malondialdehyde concentration (MDA) concentration. As shown in Figure $3 \mathrm{~A}$ and B, salt stress markedly increased the MDA concentrations in the root and leaf of $\mathrm{NaCl}-$ and $\mathrm{NaCl}+A$. aculeatus-treated plants when compared with the control. No significant difference was observed in root and leaf MDA concentrations between uninoculated and inoculated plants subjected to $200 \mathrm{mM} \mathrm{NaCl}$. Under high saline conditions (400 $\mathrm{mM} \mathrm{NaCl})$, the MDA concentration from the root and leaf of salt-treated bermudagrass plants increased by 109 and $267 \%$, respectively, when compared with the unsalinized control. However, high salt exposure accelerated the MDA concentration by only $62 \%$ and $140 \%$ in root and leaf of A. aculeatusinoculated plants.

There was no significant effect of moderate $(200 \mathrm{mM})$ salt treatment on the $\mathrm{H}_{2} \mathrm{O}_{2}$ level in the root of both treatments, when compared with the unsalinized control (Fig. 3C). When inoculated plants were exposed to both moderate and high salt concentrations, the $\mathrm{H}_{2} \mathrm{O}_{2}$ accumulation in roots was significantly lower than that in uninoculated plants (Fig. 3C). Furthermore, inoculated plants showed obviously lower $\mathrm{H}_{2} \mathrm{O}_{2}$ levels in leaves compared with uninoculated plants under high saline conditions (400 $\mathrm{mM} \mathrm{NaCl})$ (Fig. 3D).

\section{A. aculeatus enhances photosynthetic efficiency of salt-treated bermudagrass.}

As shown in Figure 4, with the increase in salinity level, there was no obvious effect to OJIP fluorescence transient of bermudagrass leaves after dark adaption. In addition, no clear K-step was observed in all curves at $0.3 \mathrm{~ms}$. However, we found that it slightly enhanced fluorescence intensity for inoculated plants when compared with uninoculated plants, regardless of $\mathrm{NaCl}$ level.

The JIP test was used to analyze basic fluorescence in order to determine the structural and functional parameters quantifying the photosynthetic behavior of the bermudagrass plants
(Supplementary Table 1). Inoculated plants treated with a high concentration $(400 \mathrm{mM} \mathrm{NaCl})$ salt stress showed significantly higher $\varphi P_{O}, \varphi E_{O}, P I_{A B S}$, and $P I_{\text {total }}$ than uninoculated plants. In detail, $P I_{A B S}$ and $P I_{\text {total }}$ were 33 and $40 \%$ higher than that of uninoculated, respectively. There were no differences among other parameters between uninoculated and inoculated plants under three $\mathrm{NaCl}$ levels.

\section{A. aculeatus induces IAA and glutathione (GSH) content of salt-treated bermudagrass.}

As shown in Table 2, the IAA concentration in leaves and roots of both treatments significantly decreased as the salinity level increased. No significant difference was observed in IAA concentration in leaves between uninoculated and inoculated plants, regardless of $\mathrm{NaCl}$ level. Strikingly, IAA concentration was also enhanced in roots for inoculated plants relative to uninoculated ones, regardless of $\mathrm{NaCl}$ level.

GSH content of both treatment plants increased with the increasing in $\mathrm{NaCl}$ concentration, to a larger extent in inoculated bermudagrass plant than uninoculated plants (Table 2). Inoculations with A. aculeatus subsequently improved the GSH in both leaves and roots compared with $\mathrm{NaCl}$ only regimes when bermudagrass was subjected to moderate $(200 \mathrm{mM})$ and high concentration $(400 \mathrm{mM})$ salt stress.

\section{Changes in ionic uptake and ionic homeostasis.}

The accumulation of $\mathrm{Na}^{+}$in the leaves and roots of both uninoculated and inoculated plants significantly increased as the salinity level increased but to a great extent in uninoculated plant (Fig. 5A and B). Compared with $\mathrm{NaCl}$-only treated, inoculation of $A$. aculeatus significantly decreased the $\mathrm{Na}^{+}$concentration in roots of bermudagrass under high $(400 \mathrm{mM} \mathrm{NaCl})$ saline conditions. The $\mathrm{K}^{+}$content decreased as salinity levels increased in the leaf and root of both treatment plants (Fig. 5C and D). There was no difference for $\mathrm{K}^{+}$concentration in leaves between uninoculated and inoculated plants, regardless of $\mathrm{NaCl}$ level. However, among plants grown in a high-saline environment, $\mathrm{K}^{+}$concentration in roots of inoculated plants was significantly higher when compared with the uncolonized plants. Salt stress caused a decline of $\mathrm{Ca}^{2+}$ concentration in leaves of bermudagrass (Fig. 5E). At the same time, no significant differences in $\mathrm{Ca}^{2+}$ concentrations in roots were observed with an increasing salinity level (Fig. 5F). A. aculeatus inoculation caused a significant increase in $\mathrm{Ca}^{2+}$ concentration of roots when compared with uninoculated plants under highly saline conditions $(400 \mathrm{mM} \mathrm{NaCl})$.

The $\mathrm{Na}^{+} / \mathrm{K}^{+}$and $\mathrm{Na}^{+} / \mathrm{Ca}^{2+}$ ratios were calculated from the $\mathrm{Na}^{+}, \mathrm{K}^{+}$, and $\mathrm{Ca}^{2+}$ concentrations. Salt treatment significantly
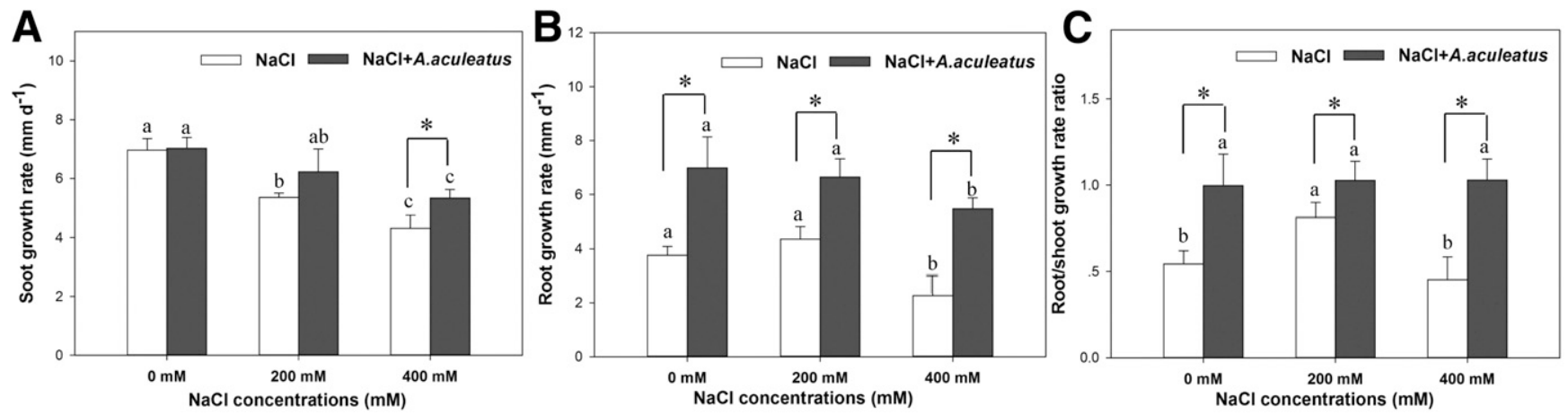

Fig. 2. Impacts of Aspergillus aculeatus on $\mathbf{A}$, shoot growth rate, $\mathbf{B}$, root growth rate, and $\mathbf{C}$, root/shoot growth rate ratio of bermudagrass at 0,200 . and $400 \mathrm{mM}$ $\mathrm{NaCl}$. Error bars are \pm standard deviation $(n=5)$. Bars marked with the same lower case letter for a given treatment (i.e., $\mathrm{NaCl}$ or $\mathrm{NaCl}+A$. aculeatus) were not significantly different for the comparison of $\mathrm{NaCl}$ concentrations, based on Student's $t$ test $(P<0.05)$. Asterisks indicate significant difference for comparisons between $\mathrm{NaCl}$ and $\mathrm{NaCl}+$ A. aculeatus treatments at a given $\mathrm{NaCl}$ concentration, based on Student's $t$ test $(P<0.05)$. 
increased the $\mathrm{Na}^{+} / \mathrm{K}^{+}$and $\mathrm{Na}^{+} / \mathrm{Ca}^{2+}$ ratios in shoots and roots of both treatments, when compared with uninoculated plants (Fig. 6). It is intriguing to note that inoculated plants showed lower $\mathrm{Na}^{+} / \mathrm{K}^{+}$ratios in leaves and roots when compared with uninoculated plants under moderate $(200 \mathrm{mM})$ and high $(400 \mathrm{mM})$ salt stress (Fig. 6A and B). Fundamentally, under moderate and high saline conditions, the $\mathrm{Na}^{+} / \mathrm{K}^{+}$ratio in roots of inoculated plants decreased by 43 and 49\%, respectively, when compared with uninoculated plants. However, there was no significant difference in the $\mathrm{Na}^{+} / \mathrm{Ca}^{2+}$ ratio in leaves between uninoculated and inoculated plants regardless of $\mathrm{NaCl}$ level (Fig. 6C). When inoculated plants were exposed to high salt concentrations $(400 \mathrm{mM})$, the $\mathrm{Na}^{+} / \mathrm{Ca}^{2+}$ ratio in roots was decreased by $56 \%$ compared with uninoculated plants (Fig. 6D).
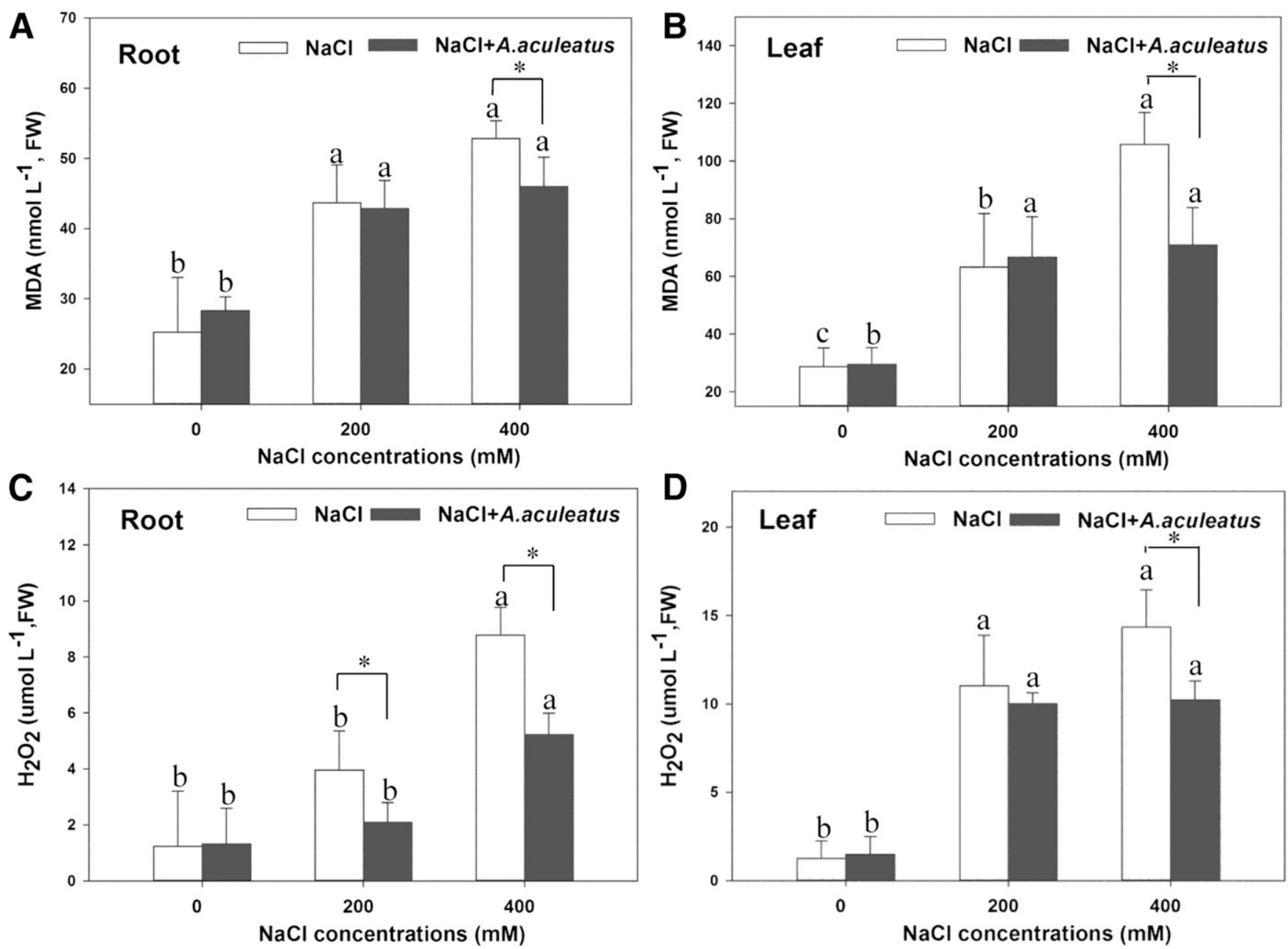

Fig. 3. A and B, Malondialdehyde (MDA) concentration and $\mathbf{C}$ and $\mathbf{D}, \mathrm{H}_{2} \mathrm{O}_{2}$ accumulation in the root and leaf of bermudagrass grown with or without Aspergillus aculeatus under 0,200, and $400 \mathrm{mM} \mathrm{NaCl}$ stress. Error bars are \pm standard deviation $(n=5)$. Bars marked with the same lower case letter for a given treatment (i.e., $\mathrm{NaCl}$ or $\mathrm{NaCl}+$ A. aculeatus) were not significantly different for the comparison of $\mathrm{NaCl}$ concentrations, based on Student's $t$ test $(P<0.05)$. Asterisks indicate significant differences for comparison between $\mathrm{NaCl}$ and $\mathrm{NaCl}+$ A. aculeatus treatments at a given $\mathrm{NaCl}$ concentration, based on Student's $t$ test $(P<0.05)$
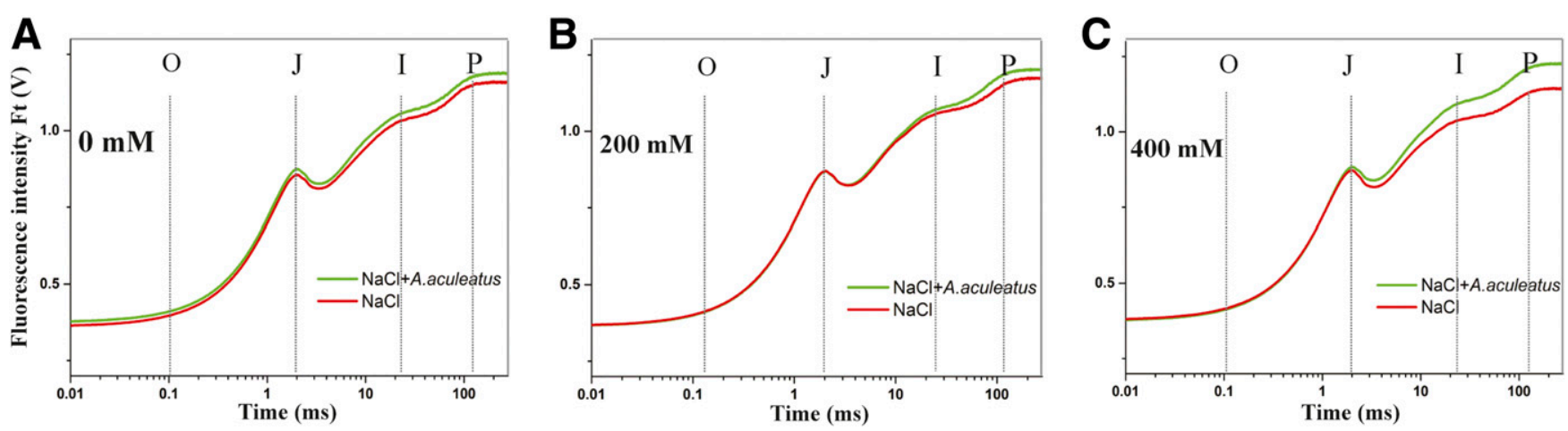

Fig. 4. Comparison of chlorophyll a fluorescence (OJIP) transient between $\mathrm{NaCl}$ and $\mathrm{NaCl}+$ Aspergillus aculeatus treatment under $\mathbf{A}, 0 \mathrm{mM}, \mathbf{B}, 200 \mathrm{mM}$, and C, $400 \mathrm{mM} \mathrm{NaCl}$ stress in bermudagrass leaves. OJIP transients were induced by 10 -s light pulse of 3,000 $\mu \mathrm{mol}$ photons $\mathrm{m}^{-2} \mathrm{~s}^{-1}$. Data for the JIP test are sampled at $10-\mu$ s intervals for the first $320 \mathrm{~ms}$. 
EC and pH value in the soil affected by $A$. aculeatus.

The soil $\mathrm{pH}$ and EC (effective concentration) value were obtained, to determine the influence of A. aculeatus on soil properties (Supplementary Fig. 2). Salt stress decreased soil $\mathrm{pH}$, as compared with the unsalinized control. Furthermore, in the inoculated treatment, the $\mathrm{pH}$ value was markedly decreased compared with the noninoculated regime, under moderate (200 mM) and high (400 mM) salt stress. Concomitantly, we found, when soil was exposed to high salt concentrations ( $400 \mathrm{mM}$ ), the EC value was increased by $23 \%$ by A. aculeatus compared with the uninoculated.

\section{DISCUSSION}

In this study, 100 and $200 \mathrm{mM} \mathrm{NaCl}$ enhanced the biomass of the tested A. aculeatus strain (Fig. 1). The inhibition effect of $\mathrm{NaCl}$ on growth was observed when A. aculeatus strain was subjected to $400 \mathrm{mM} \mathrm{NaCl}$. This result is accordant with other studies, which indicated that moderate salinity had a positive effect on the metabolism of cytoplasm, whereas high salinity restricted the growth of mycelium and decreased the content of protein (Kernaghan et al. 2002; Nagarajan and Natarajan 1999). Chen et al. (2001) found that a variety of different Pisolithus species showed growth reduction in the presence of $200 \mathrm{mM}$ $\mathrm{NaCl}$. Blomberg and Adler (1993) indicated that 50 to $200 \mathrm{mM}$ $\mathrm{NaCl}$ significantly decreased the growth of both mycelium and plants. A. aculeatus was more salt tolerant than the abovementioned fungus species, since the strain remained at a biomass similar to that in controls at $300 \mathrm{mM} \mathrm{NaCl}$.

In order to get a better understanding of the impact of A. aculeatus on the establishment of salt tolerance, we assessed important indicators of salt stress, such as plant growth and productivity, lipid peroxidation, photosynthetic behavior, and mineral nutrition. Previous studies have demonstrated that growth parameters, such as plant growth rate, turf quality, and chlorophyll concentrations in leaves has been reported to be excellent criteria to determine salinity tolerance in turfgrasses (Hu et al. 2012; Marcum 1999). In our study, higher growth rates, turf quality, and chlorophyll concentrations were observed for inoculated plants under salt-stress conditions, when compared with uninoculated plants. This showed that inoculation by A. aculeatus can alleviate the deleterious effects of salt stress. These findings are consistent with previous reports, which indicated that some microorganisms, particularly fungi and bacteria, can improve plant performance under salt stress (Baltruschat et al. 2008; Brown 1974; Waller et al. 2005). It is possible that salinity resulted in a progressive decline in the level of IAA in the root system of plants (Sakhabutdinova et al. 2003). It is also suggested that root-colonizing microorganisms that produce phytohormones may act as mechanisms for plant growth stimulation and can prevent the deleterious effects of stresses from the environment (Frankenberger and Arshad 1995). In our study, the A. aculeatus strains had the capacity to produce IAA. Strikingly, IAA concentration was also enhanced in roots for inoculated plants. Therefore, the IAA-producing fungus strain A. aculeatus also alleviated, effectively, the reductive effect of salt stress on plant growth rates, probably through its ability to produce IAA. It is essential to point out that the root growth rate of $A$. aculeatus on the bermudagrass plants occurred not only during salt stress but also in unsalinized control conditions, which implies that the fungal effect improving plant growth was not a specific process induced by salinity stress.

To better unravel the impact of A. aculeatus on the establishment of salt tolerance, we assessed biochemical markers for salt stress, such as lipid peroxidation, $\mathrm{H}_{2} \mathrm{O}_{2}$, and photosynthetic efficiency. Salt-induced lipid peroxidation was significantly attenuated in A. aculeatus-treated plants. Previous studies have demonstrated that cellular damage as a result of salt stress is associated with an accumulation of reactive oxygen species (ROS) (Hernández et al. 2000). ROS can be toxic to living cells and act as signaling molecules for stress responses. According to a recent report, endophytic fungi characterized by their broad host ranges can confer effective tolerance to ROS under salinity conditions (Rodriguez et al. 2008). Our results indicated that inoculated plants showed obviously lower $\mathrm{H}_{2} \mathrm{O}_{2}$ levels in leaves and roots compared with uninoculated plants under high salt conditions. Consistent with the $\mathrm{H}_{2} \mathrm{O}_{2}$ accumulation, the amount of lipid peroxidation (i.e., the MDA concentration) was lower in inoculation with A. aculeatus. Therefore, the A. aculeatus seemed to overcompensate the salt-induced accumulation of $\mathrm{H}_{2} \mathrm{O}_{2}$ and lipid peroxidation. GSH plays a critical role in oxidative stress by converting the oxidized GSSG to GSH (Fadzilla et al. 1997). It is also a major antioxidant that is known to protect cells from oxidative stress (Noctor et al. 1998). Moreover, GSH seems to be a signal molecule acting as a direct link between environmental stress and key adaptive responses and it plays a protective role by increasing stress tolerance (Kok and Oosterhuis 1983; May and Inzé 1998). A. aculeatus improved GSH concentration in both leaves and roots compared with $\mathrm{NaCl}$-only regimes. The increased GSH content in the inoculated plants may reflect, at least partially, a higher antioxidant defense existed in the detoxification of membrane lipid peroxidation. This suggests that enhanced tolerance to salt stress can be associated with alleviation of lipid peroxidation in A. aculeatus-inoculated plants.

Chlorophyll a fluorescence was expected to be a useful tool for investigation of plant photosynthetic efficiency under abiotic stress conditions (Chen et al. 2013). Previous studies demonstrated that salt stress caused an inhibition to PSII activity (Allakhverdiev and Murata 2008). However, other research has shown that salinity did not affect the PSII of most barley leaves (Morales et al. 1992). In this study, there is no obvious effect to OJIP fluorescence transient of bermudagrass leaves with the increase in salinity level, even when growth was seriously restricted (Fig. 4). Our results suggest that, although salinity

Table 2. Effects of Aspergillus aculeatus on indole-3-acetic acid (IAA) and glutathione (GSH) concentrations in the leaf and root of bermudagrass under 0, 200 and $400 \mathrm{mM} \mathrm{NaCl}$ stress $^{\mathrm{z}}$

\begin{tabular}{|c|c|c|c|c|c|c|c|}
\hline & \multirow[b]{2}{*}{$\mathrm{NaCl}(\mathrm{mM})$} & \multicolumn{3}{|c|}{ IAA (pmol per liter) } & \multicolumn{3}{|c|}{ GSH ( $\mu \mathrm{mol}$ per liter of fresh weight) } \\
\hline & & $\mathrm{NaCl}$ & $\mathrm{NaCl}+A$. aculeatus & $\%$ of $\mathrm{NaCl}$ & $\mathrm{NaCl}$ & $\mathrm{NaCl}+A$. aculeatus & $\%$ of $\mathrm{NaC}$ \\
\hline \multirow[t]{3}{*}{ Leaf } & 0 & 124.3 & 129.5 & 104 & 68.7 & 67.4 & 94 \\
\hline & 200 & 98.6 & 96.4 & 97.7 & 77.9 & $85.6 *$ & 109 \\
\hline & 400 & 68.3 & 70.5 & 103 & 95.6 & $109.2 *$ & 114 \\
\hline \multirow[t]{3}{*}{ Root } & 0 & 65.4 & $87.9 *$ & 134 & 25.2 & 29.6 & 117 \\
\hline & 200 & 59.6 & $79.1 *$ & 133 & 36.7 & $45.2 *$ & 123 \\
\hline & 400 & 47.2 & $67.5 *$ & 143 & 53.1 & $68.5 *$ & 129 \\
\hline
\end{tabular}

${ }^{\mathrm{z}}$ Values are means of five samples. Asterisks indicate significant differences for comparison between $\mathrm{NaCl}$ and $\mathrm{NaCl}+\mathrm{A}$. aculeatus treatments at a given $\mathrm{NaCl}$ concentration, based on Student's $t$ test $(P<0.05)$. 
impairs the growth of bermudagrass plants, plants can efficiently dissipate excessive light not needed for photosynthesis, as shown by the maintenance of an efficient photochemistry (Morales et al. 1992). This phenomenon may be due to salt-induced physiological changes leading to leaf death and not to salt itself (Morales et al. 1992). More interestingly, our results showed that fluorescence intensity was slightly enhanced for inoculated plants, as compared with uninoculated (Fig. 4). Meanwhile, $\varphi P_{O}(\mathrm{Fv} / \mathrm{Fm}), \varphi E 0, P I_{A B S}$, and $P I_{\text {total }}$ was slightly enhanced for inoculated plants under high salt concentration. The alterations of $\varphi P_{O}, \varphi E_{O}$, and performance indices $\left(P I_{A B S}\right.$ and $\left.P I_{\text {total }}\right)$ substantiate the increase in the efficiency of photosynthetic electron transport for inoculated plants. The performance indices used as an indicator of plant vitality increased significantly under the high-salinity condition for inoculated plants, as evidenced by increased chlorophyll content and high turf quality.
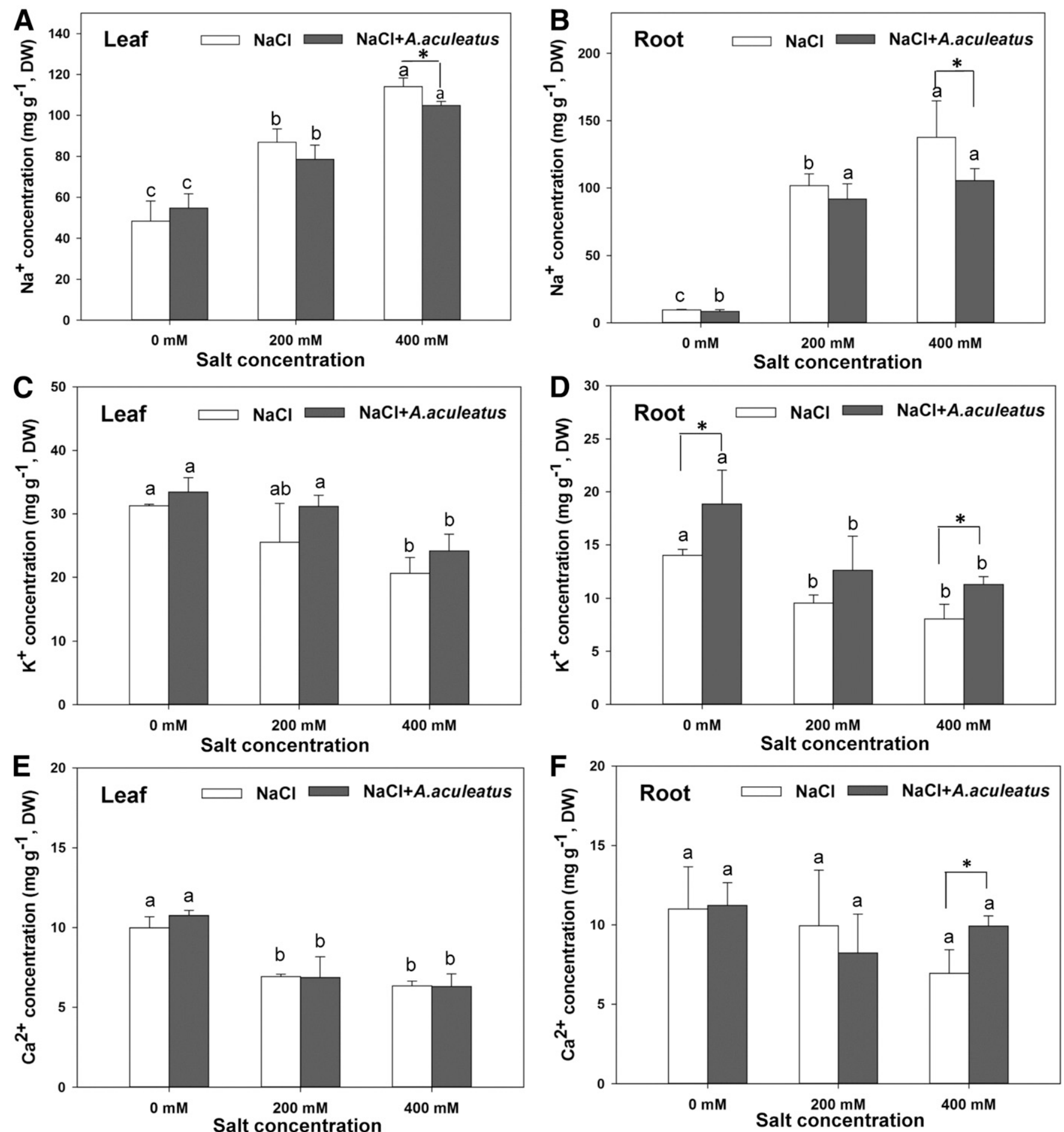

Fig. 5. $\mathbf{A}$ and $\mathbf{B}$, Effects of Aspergillus aculeatus on $\mathrm{Na}^{+}, \mathbf{C}$ and $\mathbf{D}, \mathrm{K}^{+}$, and $\mathbf{E}$ and $\mathbf{F}, \mathrm{Ca}^{2+}$ concentrations in the leaf and root of bermudagrass grown with or without A. aculeatus under 0, 200, and $400 \mathrm{mM} \mathrm{NaCl}$ stress. Error bars are \pm standard deviation $(n=5)$. Bars marked with the same lower case letter for a given treatment (i.e., $\mathrm{NaCl}$ or $\mathrm{NaCl}+$ A. aculeatus) were not significantly different for the comparison of $\mathrm{NaCl}$ concentrations, based on Student's $t$ test $(P<0.05)$. An asterisk indicates a significant difference for comparison between $\mathrm{NaCl}$ and $\mathrm{NaCl}+A$. aculeatus treatments at a given $\mathrm{NaCl}$ concentration, based on Student's $t$ test $(P<0.05)$. 
Previous research indicated that the primary effects of salt stress are through ion toxicity (Levitt 1980). The excessive accumulation of $\mathrm{Na}^{+}$in plant cells decreases photosynthesis in leaves. Salinity stress results in rapid accumulation of $\mathrm{Na}^{+}$and decreases in $\mathrm{K}^{+}$, because $\mathrm{Na}^{+}$can enter plant cells through a high-affinity $\mathrm{K}^{+}$transporter (Haro et al. 2005). This disturbs the ionic balance, causing injury. Therefore, a crucial question addressed in this study was whether $A$. aculeatus strains would also protect the bermudagrass plants from the uptake of excess $\mathrm{NaCl}$. It is noteworthy that A. aculeatus-inoculated plants exhibited reduced $\mathrm{Na}^{+}$uptake in root and shoot tissues as compared with uninoculated controls in our study. Under high saline conditions, the $\mathrm{Na}^{+}$concentration in leaves and roots of inoculated plants was 8 and $23 \%$ lower than in uninoculated plants. The diminished buildup of salt in leaf tissue is likely the result of salt uptake and transport restriction in roots (Chen et al. 2002). Our data show that A. aculeatus fungal hyphae exhibited a greater capacity for $\mathrm{Na}^{+}$absorption under saline conditions. The adsorptive rate of $\mathrm{Na}^{+}$reached maximum $(62 \%)$ at $200 \mathrm{mM} \mathrm{NaCl}$ concentrations. Therefore, an obvious assumption was that the fungus might provide a physical barrier against salt uptake into the root. It appears that the role of A. aculeatus in alleviating salt stress is partly to prevent $\mathrm{Na}^{+}$ absorption to root and translocation to shoot tissues.
In addition to an influence on $\mathrm{Na}^{+}$concentrations, $A$. aculeatus fungus improved the general nutrient status of bermudagrass, causing significant increases in $\mathrm{Ca}^{2+}$ and $\mathrm{K}^{+}$concentrations in root under high (400 mM) saline conditions (Fig. 5). Excess $\mathrm{Na}^{+}$ causes injury in plants because $\mathrm{Na}^{+}$competes with $\mathrm{K}^{+}$, leading to a depletion of $\mathrm{K}^{+}$(Tester and Davenport 2003). Our data show that $A$. aculeatus-inoculated plants accumulated significantly more $\mathrm{K}^{+}$in their leaves and roots than uninoculated plants. Therefore, A. aculeatus-inoculated plants were able to maintain a low $\mathrm{Na}^{+} / \mathrm{K}^{+}$ratio, which is a hallmark of salinity tolerance (Munns and Tester 2008). This result indicated that the disruption of ionic homeostasis was prevented in inoculated plants. Such beneficial effects on $\mathrm{K}^{+}$accumulation have also been reported for arbuscular mycorrhiza (Giri and Mukerji 2004; Langenfeld-Heyser et al. 2007). We suggest that the maintenance of a high level of $\mathrm{K}^{+}$may also contribute the alleviation of the negative effects of sodium. However, it is currently not clear how $A$. aculeatus fungus affect plant transport and uptake systems for $\mathrm{K}^{+}$.

In conclusion, our results demonstrated that a high-saline environment is well tolerated by $A$. aculeatus-inoculated bermudagrass plants. A. aculeatus facilitated bermudagrass growth, alleviated the $\mathrm{NaCl}$ toxic effects, and inhibited $\mathrm{Na}^{+}$ uptake and transport in bermudagrass. Based on our results, we
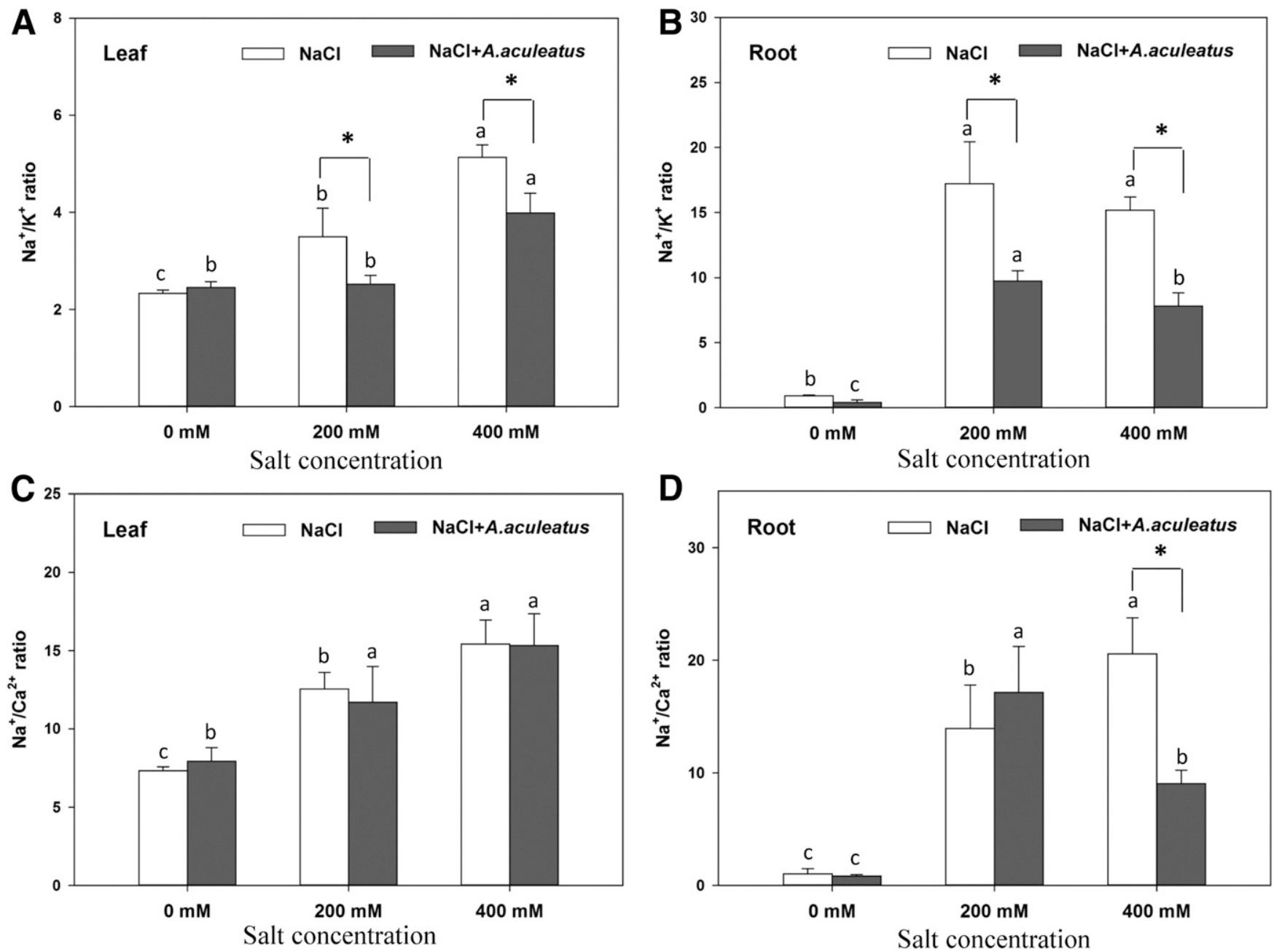

Fig. 6. Effects of Aspergillus aculeatus on $\mathbf{A}$ and $\mathbf{B}$, the $\mathrm{Na}^{+} / \mathrm{K}^{+}$ratio and $\mathbf{C}$ and $\mathbf{D}$, the $\mathrm{Na}^{+} / \mathrm{Ca}^{2+}$ ratio in the leaf and root of bermudagrass grown with or without $A$. aculeatus under 0,200 , and $400 \mathrm{mM} \mathrm{NaCl}$ stress. Error bars are \pm standard deviation $(n=5)$. Bars marked with the same lower case letter for a given treatment (i.e., $\mathrm{NaCl}$ or $\mathrm{NaCl}+A$. aculeatus) were not significantly different for the comparison of $\mathrm{NaCl}$ concentrations, based on Student's $t$ test $(P<0.05)$. Asterisks indicate significant differences for comparison between $\mathrm{NaCl}$ and $\mathrm{NaCl}+$ A. aculeatus treatments at a given $\mathrm{NaCl}$ concentration, based on Student's $t$ test $(P<0.05)$. 
deduced that differences in salt tolerance and accumulation in bermudagrass inoculated with $A$. aculeatus might be explained by the following mechanisms. A. aculeatus i) stimulated plant growth through its ability to produce IAA; ii) increased activity of antioxidases, which could decrease ROS concentrations; iii) provided a physical barrier against salt uptake into the root; and iv) prevented, in the inoculated plant, disruption of ionic homeostasis under salt stress. To the best of our knowledge, this is the first research report elucidating the characteristics and salt tolerance of the A. aculeatus strains and elucidating the role of $A$. aculeatus in salt tolerance and the oxidative system by bermudagrass with concurrent promotion of plant growth in a pot experiment. A. aculeatus might be a suitable candidate for phytoremediation processes and revegetation of salinity soil.

\section{MATERIALS AND METHODS}

\section{Effect of $\mathrm{NaCl}$ on growth and ion relations in $\mathrm{A}$. aculeatus.}

Fungal cultures. The fungus used in this study was A. aculeatus, which was obtained from isolates from the rhizosphere of bermudagrass (Xie et al. 2014). A. aculeatus isolates were cultured in Martin agar medium and liquid Martin medium. The Martin agar medium contained following components in grams per liter: glucose, $10.0 \mathrm{~g}$; peptone, $5.0 \mathrm{~g}$; $\mathrm{KH}_{2} \mathrm{PO}_{4}, 1.0 \mathrm{~g} ; \mathrm{MgSO}_{4} \cdot 7 \mathrm{H}_{2} \mathrm{O}, 0.5 \mathrm{~g}$; and agar, $18.0 \mathrm{~g}$; diluted with water to 1.0 liters, plus $1 \%$ rose bengal solution, $3.3 \mathrm{ml}$, $\mathrm{pH}$ 6.0. The A. aculeatus isolates, stored at $-80^{\circ} \mathrm{C}$, were activated with Martin agar medium on petri dishes (diameter $90 \mathrm{~mm}$ ). The petri dishes were kept in permanent darkness at $30^{\circ} \mathrm{C}$ and relative humidity was $60 \%$.

Salt treatment. For salt treatment, 100, 200, 300, 400, 600, and $800 \mathrm{mM} \mathrm{NaCl}$ was added to the liquid Martin medium, respectively. Controls were grown in the absence of $\mathrm{NaCl}$. Discs of mycelium were cut from the actively growing edge of 10-day-old colonies using a 6-mm diameter cork borer. Eventually, the discs were immersed in a 250-ml Erlenmeyer flask filled with $100 \mathrm{ml}$ of liquid Martin medium (3 discs per flask). The flasks were placed on the rotary shaker at $180 \mathrm{rpm}$ and $30^{\circ} \mathrm{C}$. The mycelium pellet and liquid Martin medium were harvested after $48 \mathrm{~h}$ of salt treatment.

The biomass of the mycelium pellet. After $48 \mathrm{~h}$ of salt treatment, the liquid medium was filtrated with qualitative filter paper. The obtained mycelium pellet was washed with deionized water to remove culture medium and, then, was air-dried at room temperature $\left(72^{\circ} \mathrm{C}\right)$ and dry weight was obtained.

Cations. For $\mathrm{Na}^{+}$determination, the over-dried mycelium pellets $(0.05 \mathrm{~g})$ were digested in a mixture of concentrated $\mathrm{HNO}_{3}, \mathrm{HF}$, and $\mathrm{HCl}(5: 2: 2, \mathrm{vol} / \mathrm{vol} / \mathrm{vol})$. The mixture was digested in an ETHOS ONE microwave sample preparation system (Milestone), using the following procedure: $12 \mathrm{~min}$ at $130^{\circ} \mathrm{C}, 25 \mathrm{~min}$ at $160^{\circ} \mathrm{C}$, and finally, $25 \mathrm{~min}$ at $180^{\circ} \mathrm{C}$. The mineral extract was adjusted to $50 \mathrm{ml}$ and was then filtrated with a $0.45-\mu \mathrm{m}$ filter membrane. The $\mathrm{Na}^{+}$concentration was determined using inductively coupled plasma optical emission spectroscopy. Each experiment was repeated at least five times.

IAA production. The IAA concentration in culture was detected with L-tryptophan, following the procedures described by Sheng et al. (2008). In brief, the A. aculeatus strain was cultured for $48 \mathrm{~h}$ in an Erlenmeyer flask containing $100 \mathrm{ml}$ of liquid Martin medium supplemented with tryptophan. After incubation, a 1-ml cell suspension was mixed with $2 \mathrm{ml}$ of Salkowski's reagent at room temperature for $15 \mathrm{~min}$, after which a pink color developed in the suspensions. The IAA concentration in culture was calculated by examining the absorbance of pink color developed after 25 min of incubation at $530 \mathrm{~nm}$. Absorbance values were calibrated using a calibration curve of pure IAA.
Effect of A. aculeatus on salt tolerance

\section{and ionic homeostasis in bermudagrass.}

Plant materials and growth conditions. Uniform stolon $(4 \mathrm{~cm}$ long) of bermudagrass 'WBD 242'were planted in solid growth substances $(1: 1$ peat soil/sand, vol//vol) in plastic pots $(15 \mathrm{~cm}$ diameter and $20 \mathrm{~cm}$ tall) on May 20, 2015. The pots were placed in a greenhouse for two months to allow for the establishment of roots and shoots, with the day and night temperatures set at $35 \pm 3^{\circ} \mathrm{C}$ and $20 \pm 3^{\circ} \mathrm{C}$, respectively, and $14 \mathrm{~h}$ light and $10 \mathrm{~h}$ dark. During the growth period, plants were irrigated three times per week and were fertilized weekly with $60 \mathrm{ml}$ of half strength Hoagland's solution (Hoagland and Arnon 1950). The grasses were hand clipped to $10 \mathrm{~cm}$ in height every week.

Fungal growth and plant-fungus concultivation. The substrate used was a mixture of coarse silica sand and sawdust (3:1; $\mathrm{vol} / \mathrm{vol}, \mathrm{pH}=6.5)$. The substrate was sieved with stainless steel mesh $(1 \mathrm{~mm})$ and was sterilized at $127^{\circ} \mathrm{C}$ for $120 \mathrm{~min}$. Subsequently, the matrices were divided into two groups, namely $\mathrm{NaCl}$ treatment only $(\mathrm{NaCl})$ and $\mathrm{NaCl}$ plus $A$. aculeatus treatment $(\mathrm{NaCl}+$ A. aculeatus $)$.

The fungus used in this study was the A. aculeatus. The isolate, stored at $-80^{\circ} \mathrm{C}$, was activated with Martin agar medium (the medium contains the following components (measured in grams per liter): glucose, $10.0 \mathrm{~g}$; peptone, $5.0 \mathrm{~g}$; $\mathrm{KH}_{2} \mathrm{PO}_{4}, 1.0 \mathrm{~g} ; \mathrm{MgSO}_{4} \cdot 7 \mathrm{H}_{2} \mathrm{O}, 0.5 \mathrm{~g}$; agar, $18.0 \mathrm{~g}$; diluted with water to 1.0 liters; plus $1 \%$ rose bengal solution, $3.3 \mathrm{ml}$ (pH 6.0) on July 18,2015 , and then, was inoculated in a 250-ml Erlenmeyer flask filled with $150 \mathrm{ml}$ of liquid Martin medium. The flask was placed on the rotary shaker at $180 \mathrm{rpm}$ and $30^{\circ} \mathrm{C}$ for $48 \mathrm{~h}$. For the $\mathrm{NaCl}+$ A. aculeatus group, the inocula of fungi isolates in liquid Martin medium were filtered with gauze and were then transferred into the substrate and mixed before the plants were transferred.

For plant-fungus cocultivation, an equal amount of grass was rinsed thoroughly, using distilled water, and then, the grass was transplanted into plastic pots $(15 \mathrm{~cm}$ in diameter and $20 \mathrm{~cm}$ deep) filled with inoculated substrate on July 20, 2015. All the pots were set into the growth chamber with standard conditions (32 and $25^{\circ} \mathrm{C}$ day and night temperatures, 14-h light and 10-h dark cycle, $60 \%$ relative humidity and photosynthetically active radiation levels at $720 \mathrm{mmol} \mathrm{m}^{-2} \mathrm{~s}^{-1}$ ) for cocultivation for two weeks.

Treatments and experimental design. After two weeks of cocultivation, the transpiration rate was measured by the difference in the plant-pot system weight on a 24-h interval. Plantpot systems with similar transpiration rates were grouped as a same replication, in order to reduce the initial differences. Subsequently, grasses were subjected to three salinity levels: $0 \mathrm{mM}$ (control), $200 \mathrm{mM}$ (moderate), and $400 \mathrm{mM}$ (high) $\mathrm{NaCl}$. Salinity was increased by daily increments of $50 \mathrm{mM} \mathrm{NaCl}$, until a final salinity level of 200 and $400 \mathrm{mM}$ was reached. After the final salinity, the shoot was clipped. The containers with plants were kept in the above-mentioned conditions for two weeks. During the period of salt exposure, the plants were irrigated daily, to maintain sufficient water and nutrition supply, with half-strength Hoagland's solution. At the end of the experiment (on August 18, 2015), the visual turf quality, canopy height, root length, and chlorophyll content were determined. Plants were separated into roots and leaves and were then immediately frozen in liquid nitrogen and stored at $-80^{\circ} \mathrm{C}$ for further subsequent analysis. The salt concentrations and treatments were arranged in a randomized complete block design with five replicates.

Measurements. Turf quality was visually assessed based on plant density, grass color (extent of chlorosis and leaf senescence), and degree of leaf wilting, using a nine-point system, in which 0 is withered yellow and dead grass, 9 is fully turgid, 
green, dense, and uniform grass, and 6 is minimum acceptable quality.

Chl was recorded using the chlorophyll meter (SPAD-502, Minolta Japan) at the end of the experiment. The content of each individual was recorded from nine fully expanded leaves with three measurements on each leaf.

Canopy height was determined by the difference in turf canopy height before and after treatment, following the procedures described by Huang and Liu (2009). In brief, canopy height was estimated by measuring four positions in each pot, using a ruler, and measurements were averaged. Shoot growth rate was the difference in canopy height before and after treatment at 2-week intervals. Root length was determined only for roots elongating before and after treatment. Subsequently, the root/shoot length ratio (average root length/canopy height) of the grass was determined.

Chlorophyll fluorescence measurements were assessed with a pulse-amplitude modulation portable chlorophyll fluorimeter (PAM 2500; Heinz Walz GmbH) with high time resolution $(10 \mu \mathrm{s})$, from the fourth fully expanded leaves at the end of the experiment. To ensure sufficient closure of PSII reaction centers and estimate the maximum fluorescence yield, the leaves were given a dark-adaptation for $30 \mathrm{~min}$. The chlorophyll fluorescence transients (OJIP curve) were determined by the measuring a red light of 3,000 $\mu \mathrm{mol}$ photons $\mathrm{m}^{-2} \mathrm{~s}^{-1}$, which was sufficient excitation intensity to obtain a true fluorescence intensity of $F_{M}$. The chlorophyll a fluorescence emission that was induced by the strong light pluses was measured and digitized between $10 \mu \mathrm{s}$ and $320 \mathrm{~ms}$. The OJIP curve was analyzed using the JIP test (chlorophyll fluorescence analysis method) (Chen et al. 2013).

MDA was determined according to the method described by Heath and Packer (1968), with slight modifications, as we described before. Briefly, fresh leaves and roots $(0.3 \mathrm{~g})$ were homogenized in trichloroacetic acid $(0.1 \% \mathrm{wt} / \mathrm{vol})$ solution. The homogenate was then centrifuged at $10,000 \times g$ for $15 \mathrm{~min}$ at $4{ }^{\circ} \mathrm{C}$ and $1 \mathrm{ml}$ of supernatant was added to $1 \mathrm{ml} 0.5 \%$ thiobarbituric acid in $20 \%$ trichloroacetic acid. The mixture was heated in a water bath at $90^{\circ} \mathrm{C}$ for $30 \mathrm{~min}$ and was then cooled on ice and centrifuged at $10,000 \times g$ for $10 \mathrm{~min}$. The MDA concentration was calculated by subtracting the nonspecific absorption at $600 \mathrm{~nm}$ from the absorption at $532 \mathrm{~nm}$ and was calibrated by using the extinction coefficient of $155 \mathrm{mM}^{-1} \mathrm{~cm}^{-1}$ (Heath and Packer 1968).

To measure the $\mathrm{H}_{2} \mathrm{O}_{2}$ content, frozen leaves and roots $(0.1 \mathrm{~g})$ were homogenized in sodium phosphate buffer $(100 \mathrm{mM}, \mathrm{pH}$ 7.8) at $4{ }^{\circ} \mathrm{C}$. The $\mathrm{H}_{2} \mathrm{O}_{2}$ content was measured with a hydrogen peroxide assay kit (S0038; Beyotime), according to the manufacturer protocols. The $\mathrm{H}_{2} \mathrm{O}_{2}$ content was calculated by examining the absorbance of the reaction buffer at $560 \mathrm{~nm}$. Absorbance values were calibrated to a standard curve generated with known concentrations of $\mathrm{H}_{2} \mathrm{O}_{2}$.

Quantification of endogenous IAA was performed with the enzyme-linked immunosorbent assay (ELISA) method according to the manufacturer protocols, as previously described by Lin et al. (2005). Briefly, frozen tissues $(0.3 \mathrm{~g})$ were ground into a fine powder with liquid nitrogen. The obtained powder was suspended in $80 \%$ methanol and centrifuged at $8,000 \times g$ for $10 \mathrm{~min}$ at $4^{\circ} \mathrm{C}$, to extract IAA. Then, the collected supernatant was immediately passed through a pre-equilibrated C18 Sep-Pak cartridge (Millipore). The efflux was collected, was dried in $\mathrm{N}_{2}$ gas, was dissolved in $100 \%$ methanol for methylation with freshly synthesized ethereal diazomethane, was dried under $\mathrm{N}_{2}$ gas, again, and was redissolved in $300 \mu \mathrm{l}$ of phosphate buffered saline for IAA ELISA, using a monoclonal antibody of high specificity for IAA methyl esterin, a standard procedure. Plant endogenous IAA was assayed and determined three times on the same extract, and samples were determined in three biological replicates.
The GSH content was measured using a commercial colorimetric assay kit, GSH-400, from OXIS International, according to the manufacturer's instructions. The GSH activity was calculated by measuring the absorbance at $420 \mathrm{~nm}$.

For $\mathrm{Na}^{+}, \mathrm{K}^{+}$, and $\mathrm{Ca}^{2+}$ determination, the oven-dried tissues were finely ground and determined as described above. Each experiment was repeated at least five times.

At the end of the experiment, the $\mathrm{pH}$ values and electrical conductivity of the substrate were determined using an Accumet AR10 meter (Fisher Scientific Inc.) and W.E.T. sensor kit (Delta-T Device Ltd.), respectively.

\section{Statistical analysis.}

All mean data were subjected to analysis of variance. Significant differences between means were performed using Student's $t$ test and multivariate analysis of variance. Differences were considered to be significant at $P<0.05$. All the statistical analyses were carried out using SPSS 20.0.

\section{ACKNOWLEDGMENTS}

This work was financially supported by the Young Scientists Fund of the National Natural Science Foundation of China (grant number 31502009) and National Natural Science Foundation of China (grant number 31672482)

\section{LITERATURE CITED}

Al-Karaki, G. N. 2000. Growth of mycorrhizal tomato and mineral acquisition under salt stress. Mycorrhiza 10:51-54.

Allakhverdiev, S. I., and Murata, N. 2008. Salt stress inhibits photosystems II and I in cyanobacteria. Photosynth. Res. 98:529-539.

Baltruschat, H., Fodor, J., Harrach, B. D., Niemczyk, E., Barna, B., Gullner, G., Janeczko, A., Kogel, K. H., Schäfer, P., Schwarczinger, I., Zuccaro, A., and Skoczowski, A. 2008. Salt tolerance of barley induced by the root endophyte Piriformospora indica is associated with a strong increase in antioxidants. New Phytol. 180:501-510.

Bandou, E., Lebailly, F., Muller, F., Dulormne, M., Toribio, A., Chabrol, J., Courtecuisse, R., Plenchette, C., Prin, Y., Duponnois, R., Thiao, M., Sylla, S., Dreyfus, B., and Bâ, A. M. 2006. The ectomycorrhizal fungus Scleroderma bermudense alleviates salt stress in seagrape (Coccoloba uvifera L.) seedlings. Mycorrhiza 16:559-565.

Blomberg, A., and Adler, L. 1993. Tolerance of fungi to $\mathrm{NaCl}$. Pages 209-232 in: Stress Tolerance of Fungi, D. H. Jennings, ed. Marcel Dekker, Inc., New York.

Blumwald, E. 2000. Sodium transport and salt tolerance in plants. Curr. Opin. Cell Biol. 12:431-434.

Brown, M. E. 1974. Seed and root bacterization. Annu. Rev. Phytopathol. 12:181-197.

Chen, D. M., Ellul, S., Herdman, K., and Cairney, J. W. 2001. Influence of salinity on biomass production by Australian Pisolithus spp. isolates. Mycorrhiza 11:231-236.

Chen, K., Chen, L., Fan, J., and Fu, J. 2013. Alleviation of heat damage to photosystem II by nitric oxide in tall fescue. Photosynth. Res. 116:21-31.

Chen, S., Li, J., Fritz, E., Wang, S., and Hüttermann, A. 2002. Sodium and chloride distribution in roots and transport in three poplar genotypes under increasing $\mathrm{NaCl}$ stress. For. Ecol. Manage. 168:217-230.

Dionisio-Sese, M. L., and Tobita, S. 2000. Effects of salinity on sodium content and photosynthetic responses of rice seedlings differing in salt tolerance. J. Plant Physiol. 157:54-58.

Fadzilla, N. A. M., Finch, R. P., and Burdon, R. H. 1997. Salinity, oxidative stress and antioxidant responses in shoot cultures of rice. J. Exp. Bot. 48: 325-331.

Feng, G., Zhang, F. S., Li, X. L., Tian, C. Y., Tang, C., and Rengel, Z. 2002. Improved tolerance of maize plants to salt stress by arbuscular mycorrhiza is related to higher accumulation of soluble sugars in roots Mycorrhiza 12:185-190.

Flowers, T., and Yeo, A. 1995. Breeding for salinity resistance in crop plants: Where next? Funct. Plant Biol. 22:875-884.

Frankenberger, J. W. T., and Arshad, M. 1995:Pages 35-71 in: Microbial synthesis of auxins. Phytohormones in soils. Marcel Dekker, New York.

Giri, B., and Mukerji, K. G. 2004. Mycorrhizal inoculant alleviates salt stress in Sesbania aegyptiaca and Sesbania grandiflora under field conditions: Evidence for reduced sodium and improved magnesium uptake. Mycorrhiza 14:307-312. 
Haro, R., Bañuelos, M. A., Senn, M. E., Barrero-Gil, J., and RodríguezNavarro, A. 2005. HKT1 mediates sodium uniport in roots. Pitfalls in the expression of HKT1 in yeast. Plant Physiol. 139:1495-1506.

Heath, R. L., and Packer, L. 1968. Photoperoxidation in isolated chloroplasts. I. Kinetics and stoichiometry of fatty acid peroxidation. Arch. Biochem. Biophys. 125:189-198.

Hernández, J. A., Jiménez, A., Mullineaux, P., and Sevilia, F. 2000. Tolerance of pea (Pisum sativum L.) to long-term salt stress is associated with induction of antioxidant defences. Plant Cell Environ. 23:853-862.

Hoagland, D. R., and Arnon, D. I. 1950. The water-culture method for growing plants without soil. Pages 357-359 in: California Agricultural Experiment Station Circular 347. University of Californa, Berkeley, CA, U.S.A.

Hosseini, F., Mosaddeghi, M. R., Hajabbasi, M. A., and Sabzalian, M. R. 2015a. Aboveground fungal endophyte infection in tall fescue alters rhizosphere chemical, biological, and hydraulic properties in texturedependent ways. Plant Soil 388:351-366

Hosseini, F., Mosaddeghi, M. R., Hajabbasi, M. A., and Sabzalian, M. R. 2015b. Influence of tall fescue endophyte infection on structural stability as quantified by high energy moisture characteristic in a range of soils. Geoderma 249-250:87-99.

Hosseini, F., Mosaddeghi, M. R., Hajabbasi, M. A., and Sabzalian, M. R. 2016. Role of fungal endophyte of tall fescue (Epichlö̈ coenophiala) on water availability, wilting point and integral energy in texturallydifferent soils. Agric. Water Manage. 163:197-211.

Hu, L., Li, H., Chen, L., Lou, Y., Amombo, E., and Fu, J. 2015. RNA-seq for gene identification and transcript profiling in relation to root growth of bermudagrass (Cynodon dactylon) under salinity stress. BMC Genomics 16:575.

Hu, L., Li, H., Pang, H., and Fu, J. 2012. Responses of antioxidant gene, protein and enzymes to salinity stress in two genotypes of perennial ryegrass (Lolium perenne) differing in salt tolerance. J. Plant Physiol. 169:146-156.

Huang, B., and Liu, L. 2009. Physiological responses of creepingbentgrass to heat stress affected by phosphonate fungicide application. Int. Turfgrass Soc. Res. J. 11:799-806.

Kernaghan, G., Hambling, B., Fung, M., and Khasa, D. 2002. In vitro selection of boreal ectomycorrhizal fungi for use in reclamation of saline-alkaline habitats. Restor. Ecol. 10:43-51.

Kok, L. J. D., and Oosterhuis, F. A. 1983. Effects of frost-hardening and salinity on glutathione and sulfhydryl levels and on glutathione reductase activity in spinach leaves. Physiol. Plant. 58:47-51.

Langenfeld-Heyser, R., Gao, J., Ducic, T., Tachd, P., Lu, C. F., Fritz, E., Gafur, A., and Polle, A. 2007. Paxillus involutus mycorrhiza attenuate $\mathrm{NaCl}$-stress responses in the salt-sensitive hybrid poplar Populus $\times$ canescens. Mycorrhiza 17:121-131.

Levitt, J. 1980. Responses of Plants to Environmental Stress. Academic Press, New York.

Li, J., Bao, S., Zhang, Y., Ma, X., Mishra-Knyrim, M., Sun, J., Sa, G., Shen, X., Polle, A., and Chen, S. 2012. Paxillus involutus strains MAJ and NAU mediate $\mathrm{K}+/ \mathrm{Na}+$ homeostasis in ectomycorrhizal Populus $\times$ canescens under $\mathrm{NaCl}$ stress. Plant Physiol. 159:1771-1786.

Lin, W. H., Wang, Y., Mueller-Roeber, B., Brearley, C. A., Xu, Z. H., and Xue, H. W. 2005. At5PTase 13 modulates cotyledon vein development through regulating auxin homeostasis. Plant Physiol. 139:1677-1691.

Malinowski, D. P., Alloush, G. A., and Belesky, D. P. 2000. Leaf endophyte Neotyphodium coenophialum modifies mineral uptake in tall fescue. Plant Soil 227:115-126.

Marcum, K. B. 1999. Salinity tolerance mechanisms of grasses in the subfamily Chloridoideae. Crop Science 39:1153-1160.

Maxwell, K., and Johnson, G. N. 2000. Chlorophyll fluorescence-A practical guide. J. Exp. Bot. 51:659-668.

May, M. J., and Inzé, D. 1998. Glutathione homeostasis in plants: Implications for environmental sensing and plant development. J. Exp. Bot. 49:649-667.
Morales, F., Abadía, A., Gómez-Aparisi, J., and Abadía, J. 1992. Effects of combined $\mathrm{NaCl}$ and $\mathrm{CaCl}_{2}$ salinity on photosynthetic parameters of barley grown in nutrient solution. Physiol. Plant. 86:419-426.

Munns, R. 2002. Comparative physiology of salt and water stress. Plant Cell Environ. 25:239-250.

Munns, R. 2005. Genes and salt tolerance: Bringing them together. New Phytol. 167:645-663.

Munns, R., and Tester, M. 2008. Mechanisms of salinity tolerance. Annu. Rev. Plant Biol. 59:651-681.

Nagarajan, G., and Natarajan, K. 1999. The use of Box-Behnken design of experiments to study in vitro salt tolerance by Pisolithus tinctorius. World J. Microbiol. Biotechnol. 15:197-203.

Noctor, G., Arisi, A.C.M., Jouanin, L., Kunert, K.J., Rennenberg, H., and Foyer, C.H. 1998. Glutathione: Biosynthesis, metabolism and relationship to stress tolerance explored in transformed plants. J. Exp. Bot. 49: 623-647.

Pessarakli, M., and Szabolcs, I. 2011. Soil salinity and sodicity as particular plant/crop stress factors. Pages 3-21 in: Handbook of Plant and Crop Stress, 3rd Ed., M. Pessarakli, ed. Taylor and Francis, Boca Raton, FL, U.S.A.

Rodriguez, R. J., Henson, J., Van Volkenburgh, E., Hoy, M., Wright, L., Beckwith, F., Kim, Y. O., and Redman, R. S. 2008. Stress tolerance in plants via habitat-adapted symbiosis. ISME J. 2:404-416.

Sakhabutdinova, A. R., Fatkhutdinova, D. R., Bezrukova, M. V., and Shakirova, F. M. 2003. Salicylic acid prevents the damaging action of stress factors on wheat plants. Bulg. J. Plant Physiol. Special Issue:314319.

Shannon, M. C. 1997. Adaptation of plants to salinity. Adv. Agron. 60:75120.

Shaul, O., Galili, S., Volpin, H., Ginzberg, I., Elad, Y., Chet, I., and Kapulnik, Y. 1999. Mycorrhiza-induced changes in disease severity and PR protein expression in tobacco leaves. Mol. Plant-Microbe Interact 12: 1000-1007.

Sheng, X. F., Xia, J. J., Jiang, C. Y., He, L. Y., and Qian, M. 2008. Characterization of heavy metal-resistant endophytic bacteria from rape (Brassica napus) roots and their potential in promoting the growth and lead accumulation of rape. Environ. Pollut. 156:1164-1170.

Smith, S. E., and Read, D. J. 2010. Mycorrhizal Symbiosis. Academic Press, New York.

Tester, M., and Davenport, R. 2003. $\mathrm{Na}^{+}$tolerance and $\mathrm{Na}^{+}$transport in higher plants. Ann. Bot. (Lond.) 91:503-527.

Tian, C., Feng, G., Li, X., and Zhang, F. 2004. Different effects of arbuscular mycorrhizal fungal isolates from saline or non-saline soil on salinity tolerance of plants. Appl. Soil Ecol. 26:143-148.

Waller, F., Achatz, B., Baltruschat, H., and Kogel, K.-H. 2005. The endophytic fungus Piriformospora indica reprograms barley to saltstress tolerance, disease resistance, and higher yield. Proc. Natl. Acad. Sci. U.S.A. 102:13386-13391.

Wang, W., Vinocur, B., and Altman, A. 2003. Plant responses to drought, salinity and extreme temperatures: Towards genetic engineering for stress tolerance. Planta 218:1-14.

Wang, W., Vinocur, B., Shoseyov, O., and Altman, A. 2000. Biotechnology of plant osmotic stress tolerance physiological and molecular considerations. Pages 285-292 in: IV International Symposium on In Vitro Culture and Horticultural Breeding, International Society for Horticultural Science, Brussels.

Xie, Y., Fan, J., Zhu, W., Amombo, E., Lou, Y., Chen, L., and Fu, J. 2016. Effect of heavy metals pollution on soil microbial diversity and bermudagrass genetic variation. Front. Plant Sci. 7:755.

Xie, Y., Luo, H., Du, Z., Hu, L., and Fu, J. 2014. Identification of cadmiumresistant fungi related to $\mathrm{Cd}$ transportation in bermudagrass [Cynodon dactylon (L.) Pers]. Chemosphere 117:786-792.

Zhu, J.-K. 2001. Plant salt tolerance. Trends Plant Sci. 6:66-71. 